\title{
Factors associated with postnatal care utilization among postpartum women in Ethiopia: a multi-level analysis of the 2016 Ethiopia demographic and health survey
}

\author{
Bezawit Adane ${ }^{1 *}$, Girmatsion Fisseha ${ }^{2}$, Getaw Walle ${ }^{1}$ and Melaku Yalew ${ }^{3}$
}

\begin{abstract}
Background: Most postpartum women and newborns do not utilize postnatal care due to less emphasis given especially in developing countries. Understanding individual and community-level factors associated with postnatal care will help to design appropriate strategies and policies for improving service utilization. Therefore, this study aimed to assess individual and community-level factors associated with postnatal care utilization in Ethiopia.

Method: This study used the Ethiopian Demographic and Health Survey (EDHS) data of 2016. A total of 4489 women who gave birth 2 years before the survey were included. Two-stage stratified cluster sampling technique was used. The analysis was done using Stata version 14.0 after checking for basic assumptions of multilevel logistic regression. Multilevel mixed-effects logistic regression was used to identify determinants of postnatal care utilization. An adjusted odds ratio with a 95\% confidence interval was used to show the strength and direction of the association.

Results: Husband with secondary education $[A O R=0.17,95 \% \mathrm{Cl}=(0.04,0.68)]$, four or more antenatal care visit $[A O R=10.77,95 \% \mathrm{Cl}=(2.65,43.70)]$, middle wealth quintile $[\mathrm{AOR}=3.10,95 \% \mathrm{Cl}=(1.12,8.58)]$ were individual level factors. Community level education $[A O R=2.53,95 \% \mathrm{Cl}=(1.06,6.06)]$ and community level of health service utilization $[A O R=2.32,95 \% \mathrm{Cl}=(1.14,4.73)]$ were the predictors at community level.

Conclusion: Wealth index, number of antenatal care visits, husband education, community level of education and health service utilization were significantly associated with PNC service utilization. Provision of quality antenatal care, improvement of the educational status of women and husband involvement in PNC are important strategies to increase PNC service utilization.
\end{abstract}

Keywords: Postnatal care utilization, Factor associated, Multi-level analysis, Ethiopia

* Correspondence: adanebeza1987@gmail.com

'Department of Biostatistics and Epidemiology, School of Public Health, College of Medicine and Health Sciences, Wollo University, Dessie, Ethiopia

Full list of author information is available at the end of the article

C The Author(s). 2020 Open Access This article is licensed under a Creative Commons Attribution 4.0 International License, which permits use, sharing, adaptation, distribution and reproduction in any medium or format, as long as you give appropriate credit to the original author(s) and the source, provide a link to the Creative Commons licence, and indicate if changes were made. The images or other third party material in this article are included in the article's Creative Commons licence, unless indicated otherwise in a credit line to the material. If material is not included in the article's Creative Commons licence and your intended use is not permitted by statutory regulation or exceeds the permitted use, you will need to obtain permission directly from the copyright holder. To view a copy of this licence, visit http://creativecommons.org/licenses/by/4.0/. The Creative Commons Public Domain Dedication waiver (http://creativecommons.org/publicdomain/zero/1.0/) applies to the data made available in this article, unless otherwise stated in a credit line to the data. 


\section{Background}

Postnatal care (PNC) is a constellation of critical care given after childbirth to mothers and her newborn [1]. The postpartum period starts from $1 \mathrm{~h}$ after the delivery of the placenta and ends 6 weeks after delivery [2]. According to World Health Organization (WHO), the mother and newborn should receive PNC during the first $24 \mathrm{~h}$ after birth if birth is in a health facility. Whereas, the first postnatal contact should be as early as possible within $24 \mathrm{~h}$ if the birth is at home and at least three additional contacts are recommended for all mothers and newborns on day $3(48-72 \mathrm{~h})$, between day 7 to day 14 and 6 weeks after birth [3].

It is the most important maternal health care service for the prevention and management of physical and mental impairment as well as a disability that occurs during the postnatal period [3]. It is also very essential for the health of both the mother and the child [4, 5]. Despite its importance, it is the most neglected maternal health service particularly in developing countries [6-9]. The Demographic and Health Survey (DHS) results of different African countries indicated that only 36\% of women had a postnatal visit within 2 days [10] but, it was much less in Ethiopia which was 17\% according to 2016 EDHS [11].

The postnatal period is a risk period in which most of the maternal and neonatal mortality happen, especially in the first $24 \mathrm{~h}$ [3]. WHO reported that $28 \%$ of maternal mortality occurred in the intra-partum and immediate postpartum period and the rest $36 \%$ were between $24 \mathrm{~h}$ to 42 days postpartum [12]. Out of all live births, an estimated 3.7 to 4 million deaths occur in the first 28 days of life [13]. About half of these deaths occur on the first day of life, and more than two-thirds within the first week of life [14].

Although, policies and programs have largely stressed this critical period still the implementation is poor [3]. Sustainable Development Goals (SDG) came into action particularly SDG-3 which provides a new strategy, by the year 2030 to reduce neonatal and maternal mortality to below 12 per 1000 and 70 per 100,000 live births respectively [15]. Besides, Ethiopian government adopts Health Sector Transformation Plan (HSTP) which aims to decrease maternal mortality ratio (MMR) from 420 to 199 per 100,000 live birth and infant and neonatal mortality rates from 44 and 28 to 20 and 10 per 1000 live births by $2020[16,17]$. Regardless of efforts made by the Ethiopian government, the use of postnatal care services is still very low [11].

The factors which determine the utilization of PNC services differ from place to place, from individual to community which is affected by the culture and belief of women [18-24]. Even though the factors for PNC service utilization were from different levels, those previous studies conducted in Ethiopia simple regression model of analysis and the sample sizes were covering only specific or local areas [25-27]. Since the assumption of independence among observations within the same cluster and equal variance between clusters is violated in the case of nested data. Regressing factors from different levels by using a standard binary regression model leads to bias and loss of power. In addition to this, such type of analysis may result in either atomistic or ecological fallacy. So, this study aimed to assess individual and community-level factors associated with postnatal care utilization among postpartum women using the 2016 EDHS Dataset.

\section{Methods and materials}

\section{Study area and design}

A cross-sectional study design using secondary analysis of 2016 Ethiopia DHS data was used. The 2016 survey was the recent EDHS Which was conducted by the Central Statistical Agency (CSA), Federal Minister of Health $(\mathrm{FMoH})$ and Ethiopian Public Health Institute (EPHI) with technical assistance from the International Classification of Functioning (ICF) [11]. Ethiopia is located in the North-Eastern part of Africa, also known as the horn of Africa, lies between $3^{\circ}$ and $15^{\circ}$ North latitude and $33^{\circ}$ and $48^{\circ}$ East longitudes. It borders six countries Eritrea, Djibouti, Somalia, Kenya, South Sudan, and Sudan and it covers an area of 1.1 million square kilometers ranging from $4,620 \mathrm{~m}$ above sea level to $148 \mathrm{~m}$ below sea level [28]. It has a total of $110,582,083$ populations, of which 55,047,955 were women [29].

\section{Study population and sample size}

A total of 4489 women who gave birth in the 2 years before the survey (January 18, 2016) from the Ethiopian DHS 2016 dataset were included from nine geographical regions and two administrative cities of Ethiopia. Women who gave birth at the health facility and get PNC service before being discharged from the health facility were excluded from the analysis (Fig. 1).

\section{Variable measurement}

The outcome variable (PNC utilization was measured if a woman received at least one visit/care during the first week after discharge or delivery at home [30]. Women's autonomy was measured by the decision-making power in the household using the following three questions. Who decides matters about the woman's health, major purchases, and visits to friends or family? A woman, who made more than one decision, either alone or jointly with her husband, was categorized as having high autonomy, a woman who made one or no decision making was categorized as having autonomy [31]. Attitude towards wife-beating was measured based on five hypothetical scenarios: did she goes out without telling him, 
Did she neglects the children, Did she argues with him, did she refuses to have sexual intercourse with him and did she doesn't cook food properly. Based on the above listed scenarios, if the woman agreed that her husband had a right to beat her in any of these five hypothetical scenarios, she was classified as having favorable attitudes toward domestic violence against women. If she doesn't agree with any of these hypothetical scenarios, she was classified as having opposing attitudes toward domestic violence [31].

\section{Data processing and analysis}

Data cleaning was conducted to check for consistency and missing value. Recoding, labeling, and exploratory analysis were performed. Categorization and recategorization were done for different variables according to the result of different kind of literature. Descriptive statistics were used to present frequencies, with percentages in tables, graphs and using texts. For analysis, Stata/SE version 14.0 was used. Sample weight was used to compensate for the unequal probability of selection between the strata that were geographically defined, as well as for non-responses. Any further explanation regarding the sample weighting procedure can be founded in the EDHS methodology report [11].

Multilevel analysis was conducted after checking that the data was eligible for multilevel analysis (Intra-class Correlation Coefficient (ICC) greater than 10\% (ICC = $42 \%)$ ). Since DHS data are hierarchical, i.e. individuals (level 1) were nested within communities (level 2), a two-level mixed-effects logistic regression model was fitted to estimate both independent (fixed) effects of the explanatory variables and community-level random effects on postnatal care utilization. Because the log of the probability of PNC utilization will be modeled using a two-level multilevel model as follows [32]:

$$
\log \left[\frac{\Pi i j}{1-\Pi i j}\right]=\beta_{0}+\beta_{1} \mathrm{X}_{\mathrm{ij}}+\mathrm{B}_{2} \mathrm{Z}_{\mathrm{ij}}+\mu_{\mathrm{j}}+\mathrm{e}_{\mathrm{ij}}
$$

Where, $i$ and $j$ are the level 1 (individual) and level 2 (community) units, respectively; $\mathrm{X}$ and $\mathrm{Z}$ refer to individual and community-level variables, respectively; $\pi i j$ is the probability of PNC utilization for the $\mathrm{i}^{\text {th }}$ women in the $j^{\text {th }}$ community; the $\beta$ 's will be the fixed coefficients. Whereas, $\beta 0$ is the intercept-the effect on the probability of PNC use in the absence of influence of predictors; and uj showed the random effect (effect of the community on PNC) for the $j^{\text {th }}$ community and eij showed random errors at the individual levels. By assuming each community had different intercept $(\beta 0)$ and fixed coefficient $(\beta)$, the clustered data nature and the within and between community variations will be taken in to account.
During analysis first, bivariable multilevel logistic regression was fitted and variables with $p$-value less than 0.2 were selected to build the 3 models (model1-3). Then the analysis was performed in four steps: Model 0 (empty model/ without explanatory variable); Model 1 (only individual-level factors) Model 2 (only communitylevel factors); and Model 3 (both individual and community-level factors). The measures of association (fixed-effects) estimate the associations between the likelihood of women to use PNC and various explanatory variables were expressed as Adjusted Odds Ratio (AOR) with their $95 \%$ confidence level. A variable in which the confidence interval does not include the null value and $p$-value $<0.05$ was used to define statistical significance. The measures of variation (random-effects) were reported using ICC, Median Odds Ratio (MOR) and proportional change in variance (PCV) to measure the variation between clusters. The ICC was used to explain how much the observation in the same cluster resembled each other while MOR is a measure of unexplained cluster heterogeneity. The ICC was calculated as follows: [ICC $\left.=\frac{\delta^{2}}{\delta^{2+\frac{\pi^{2}}{3}}}\right], \delta^{2}$ where is the estimated variance of clusters. MOR is defined as the median value of the odds ratio between the area at highest risk and the area at the lowest risk when randomly picking out two areas and it was calculated using the formula $[\mathrm{MOR}=\exp$. ( $\left.\left.\sqrt{2 x \delta^{2}+0.6745}\right) \approx \exp (0.95 \delta)\right]$. In this study, MOR shows the extent to which the individual probability of using PNC is determined by the residential area. The proportional change in variance (PCV) measures the total variation attributed by individual-level factors and area-level factors in the multilevel model. The formula for PCV and MOR has been described elsewhere [32]. The presence of Multicollinearity was checked among independent variables using standard error at the cutoff point of ${ }_{ \pm} 2$ and there was no Multicollinearity. The loglikelihood test and area under the ROC (Receiver Operating Characteristic) curve were used to estimate the goodness of fit of the adjusted final model in comparison to the preceding models. The area under the curve of each subsequent model was computed (Fig. 2).

\section{Results}

\section{Socio-demographic characteristics of the respondent}

The total numbers of women who gave birth within 2 years before the survey and included for analysis were 4489 mothers. Out of this, 3297 (73.4\%) were founded in the age group 20-34 years. Looking at the age at first marriage, $1769(39.40 \%)$ married between ages 16-19 years. About 4269 (95\%) were currently married and 1646 (36.6\%) were employed. From the total husbands of the women 1924 (45.35\%) had no education and 3761 (88.60\%) husbands were employed, 1889 (42.08\%) women 


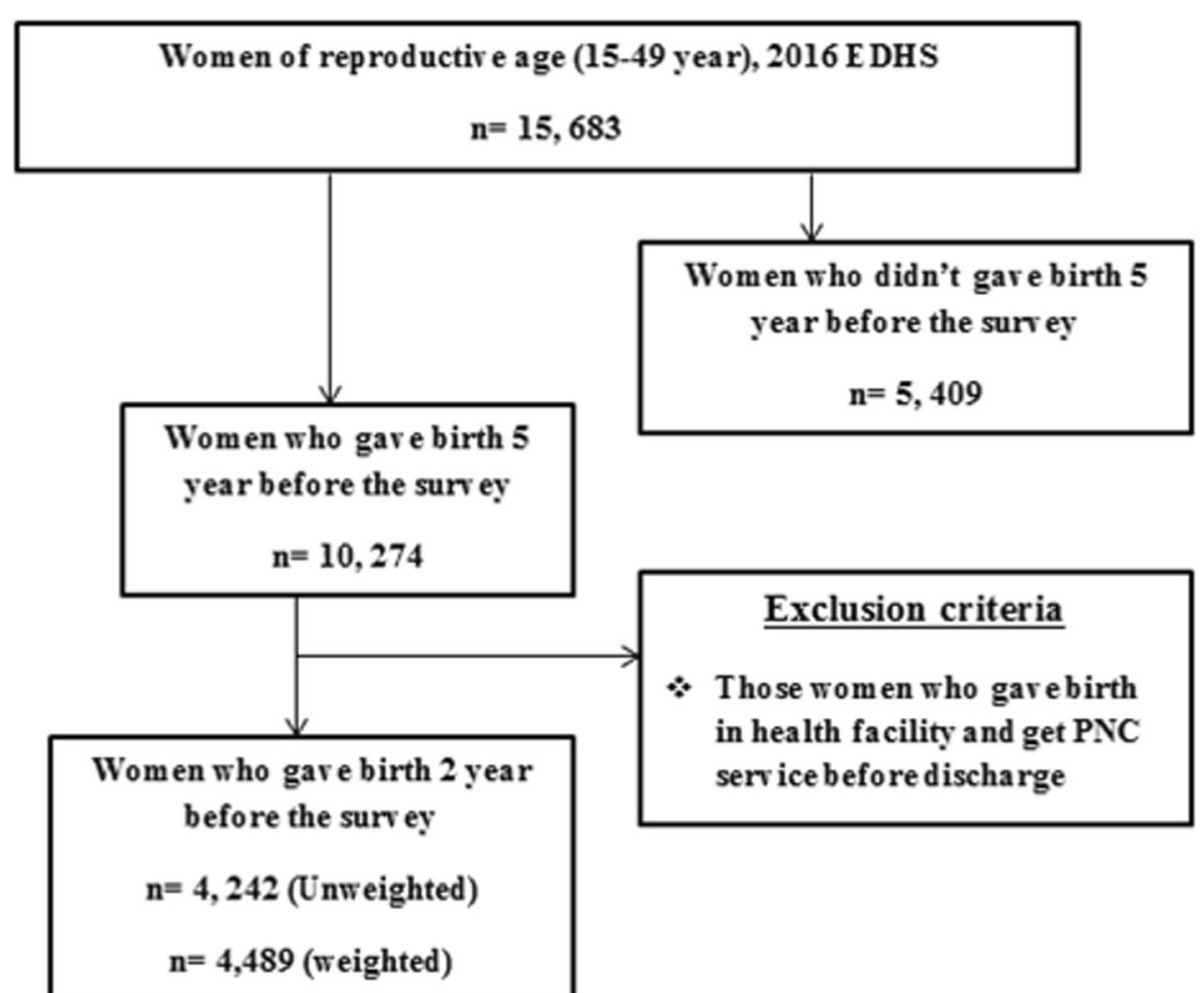

Fig. 1 --+Sampling and exclusion procedures to identify the final sample size in 2016 EDHS

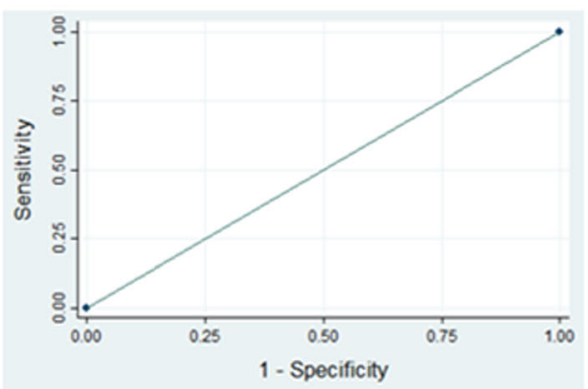

Area under ROC curve for null model $=0.5000$

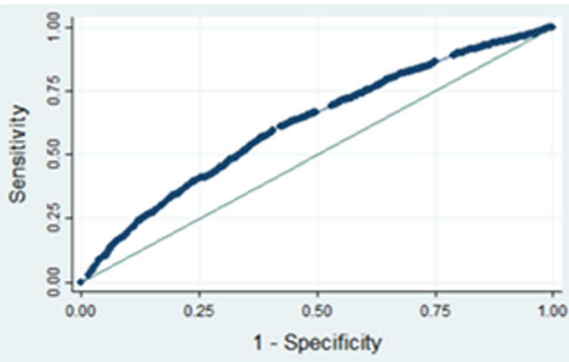

Area under ROC curve for model $2=0.6187$

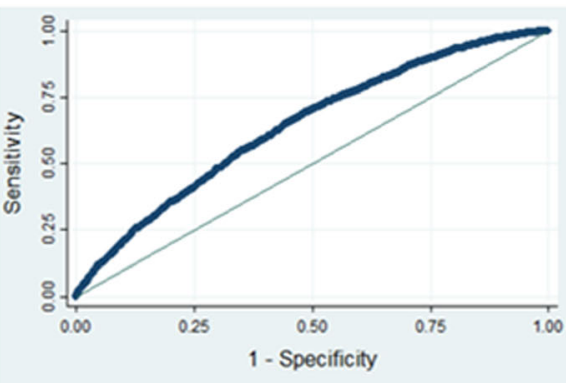

Area under ROC curve for model $1=0.6401$

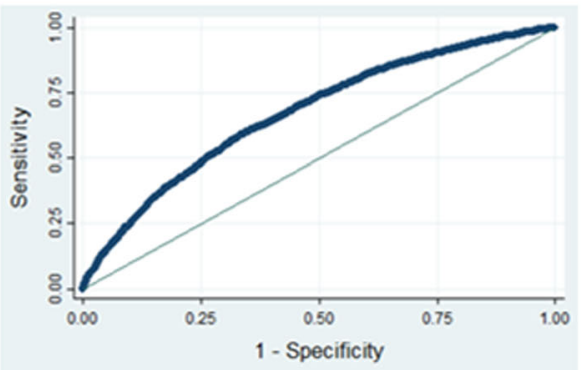

Area under ROC curve $=0.6713$

Fig. 2 The area under the ROC curve for each model (null model, model 1, model 2 and mode 3) in 2016 EDHS 
had birth orders 2 to 4, about 1602 (37.61\%) women gave birth at the health facility. Three thousand three hundred seventeen $(73.90 \%)$ wanted their last child (Table 1$)$.

\section{Reproductive history}

Regarding ANC visit, 1595 (35.54\%) of women had no ANC visit, whereas 1495 (33.30\%) had four and above ANC visits. About 4369 (97.34\%) women gave birth via cesarean section, and 489 (11.47\%) had low women autonomy. From the total last newborns, 2311 (51.48\%) were female and about $1812(40.82 \%)$ had average size at birth. Out of the total study participants 3953 (88.07\%) resided in a rural area, $2710(60.38 \%)$ responded that distance to the health facility was far and 2006 (44.69\%) resided in Oromia region. The median and interquartile range (IQR) for the proportion of women employed and the proportion of women who had a negative attitude towards wife-beating were 28.57 (36.7) and 60 (41.6) respectively (Table 2).

\section{Individual and community level factors for PNC utilization} (fixed effects)

After adjusting for individual and community level factors (model 3), the educational status of husband,

Table 1 Socio-demographic characteristics of women in Ethiopia who gave birth within 2 years before the survey, EDHS $2016(n=4489)$

\begin{tabular}{llll}
\hline Variables & Category & Frequency & Percentage \\
\hline Age & $15-19$ & 287 & 6.39 \\
& $20-34$ & 3297 & 73.46 \\
Marital status & $35-49$ & 904 & 20.14 \\
& Never in union & 32 & 0.70 \\
& Formerly married & 188 & 4.18 \\
Age at first marriage & Currently married & 4269 & 95.12 \\
& $<16$ years & 1708 & 38.05 \\
& 16-19years & 1769 & 39.40 \\
Educational status & N19years & 1013 & 22.55 \\
& No education & 2736 & 60.95 \\
& Primary & 1355 & 30.18 \\
& Secondary & 268 & 5.98 \\
& Higher & 130 & 2.89 \\
Occupation & Not employed & 2843 & 63.34 \\
& Employed & 1646 & 36.66 \\
Husband Education & No education & 1924 & 45.35 \\
& Primary & 1710 & 40.29 \\
& Secondary & 393 & 9.27 \\
& Higher & 216 & 5.09 \\
& Not Employed & 484 & 11.40 \\
& Employed & 3761 & 88.60 \\
\hline
\end{tabular}

Table 2 Obstetric and related characteristics of women in Ethiopia who gave birth within 2 years before the survey, EDHS $2016(n=4489)$

\begin{tabular}{|c|c|c|c|}
\hline Variables & Category & Frequency & Percentage \\
\hline \multirow[t]{3}{*}{ Birth order } & 1 & 912 & 20.31 \\
\hline & $2-4$ & 1889 & 42.08 \\
\hline & $\geq 5$ & 1688 & 37.61 \\
\hline \multirow[t]{2}{*}{ Place of delivery } & Home & 2887 & 64.31 \\
\hline & Health facility & 1602 & 35.69 \\
\hline \multirow[t]{2}{*}{ The last child wanted } & No & 1172 & 26.10 \\
\hline & Yes & 3317 & 73.90 \\
\hline \multirow[t]{3}{*}{ No of ANC visit } & 0 & 1595 & 35.54 \\
\hline & $1-3$ & 1399 & 31.16 \\
\hline & $\geq 4$ & 1495 & 33.30 \\
\hline \multirow[t]{2}{*}{ Mode of delivery } & Cesarean section & 4369 & 97.34 \\
\hline & Vaginal & 119 & 2.66 \\
\hline \multirow[t]{2}{*}{ Women autonomy } & Low & 489 & 11.47 \\
\hline & High & 3779 & 88.53 \\
\hline \multirow{2}{*}{$\begin{array}{l}\text { Attitude towards } \\
\text { wife-beating }\end{array}$} & Opposing & 2485 & 55.51 \\
\hline & Favorable & 1991 & 44.49 \\
\hline
\end{tabular}

numbers of ANC visits, household wealth index and community level of education and health service utilization were significantly associated with PNC utilization. Independent of other factors, women whose husband had secondary education were $83 \%$ less likely to use PNC as compared to women whose husband had higher education $[\mathrm{AOR}=0.17,95 \% \mathrm{CI}=(0.04,0.68)]$. Those women who had 1-3 ANC visits were 7 times more likely to utilize PNC service as compared to women who had no $\mathrm{ANC}$ visit $[\mathrm{AOR}=7.27,95 \% \mathrm{CI}=$ $(1.81,29.27)]$. likewise, women who had four and above ANC visits were 11 times more likely to use PNC service as compared to women without ANC visit [AOR = $10.77,95 \% \mathrm{CI}=(2.65,43.70)]$. Looking at the wealth of household, women who live in the middle wealth quintile were 3 times more likely to utilize PNC than women who live in the poorest wealth quintile [AOR $=3.10,95 \%$ $\mathrm{CI}=(1.12,8.57)]$. Among community-level variables, community level of education and community level of health service utilization showed a statistically significant association. Those women who lived in a community with a high level of education were 2.5 times more likely to use PNC as compared to women who lived in a community with a low level of education $[\mathrm{AOR}=2.53,95 \%$ $\mathrm{CI}=(1.06,6.06)]$. Similarly, women who lived in the community who had a high level of health service utilization were 2 times more likely to have PNC utilization as compared to women who lived in community with a low level of health service utilization [AOR = $2.32,95 \% \mathrm{CI}=(1.14,4.73)]$ (Table 3). 
Table 3 Multilevel logistic regression analysis of individual and community-level factors associated with PNC in Ethiopia, EDHS 2016

\begin{tabular}{|c|c|c|c|c|c|}
\hline Individual and community level characteristics & COR $(95 \% \mathrm{Cl})$ & $\begin{array}{l}\text { Model } 0 \\
\boldsymbol{n}=4242 \\
\mathrm{ICC}=42 \% \\
\end{array}$ & $\begin{array}{l}\text { Model } 1 \\
\text { AOR }(95 \% \mathrm{Cl}) \\
\boldsymbol{n}=4000\end{array}$ & $\begin{array}{l}\text { Model } 2 \\
\text { AOR(95\% Cl) } \\
\boldsymbol{n}=4206\end{array}$ & $\begin{array}{l}\text { Model } 3 \\
\text { AOR }(95 \% \mathrm{Cl}) \\
\boldsymbol{n}=3967\end{array}$ \\
\hline \multicolumn{6}{|l|}{ Educational Status of women } \\
\hline No education & 1 & & 1 & & 1 \\
\hline Primary & $1.19(0.63,2.25)$ & & $0.98(0.47,2.07)$ & & $0.86(0.40,1.86)$ \\
\hline Secondary & $1.95(0.76,4.97)$ & & $1.15(0.41,3.23)$ & & $0.94(0.35,2.51)$ \\
\hline Higher & $3.97(1.09,14.35)$ & & $2.92(0.78,11.01)$ & & $1.98(0.54,7.31)$ \\
\hline \multicolumn{6}{|l|}{ Occupation of women } \\
\hline Not employed & 1 & & 1 & & 1 \\
\hline Employed & $1.66(0.91,3.03)$ & & $1.43(0.77,2.66)$ & & $1.26(.62,2.55)$ \\
\hline \multicolumn{6}{|l|}{ Place of delivery } \\
\hline Home & 1 & & 1 & & 1 \\
\hline Health facility & $2.25(1.18,4.27)$ & & $1.19(0.58,2.45)$ & & $1.01(0.48,2.12)$ \\
\hline \multicolumn{6}{|l|}{ Number of ANC visits } \\
\hline No & 1 & & 1 & & 1 \\
\hline $1-3$ & $7.27(2.29,22.97)$ & & $8.3(2.12,32.35)$ & & $7.27(1.8,29.27)^{*}$ \\
\hline$>=4$ & $12.0(3.84,37.51)$ & & $12.24(3.1,8.24)$ & & $10.8(2.65,43.7)^{*}$ \\
\hline \multicolumn{6}{|l|}{ Women autonomy } \\
\hline Low & 1 & & 1 & & 1 \\
\hline High & $2.64(.87,7.96)$ & & $2.02(0.58,6.7)$ & & $2.09(0.65,6.74)$ \\
\hline \multicolumn{6}{|l|}{ Media exposure } \\
\hline No exposure & 1 & & 1 & & 1 \\
\hline Low exposure & $2.42(1.23,4.76)$ & & $1.43(0.70,2.91)$ & & $1.27(0.62,2.60)$ \\
\hline High exposure & $1.11(.56,2.20)$ & & $0.4(0.19,1.18)$ & & $0.47(0.18,1.23)$ \\
\hline \multicolumn{6}{|l|}{ Wealth Index } \\
\hline Poorest & 1 & & 1 & & 1 \\
\hline Poorer & $1.19(0.39,3.56)$ & & $0.97(0.32,2.9)$ & & $0.96(0.32,2.84)$ \\
\hline Middle & $4.08(1.58,10.52)$ & & $2.87(1.08,7.7)$ & & $3.10(1.12,8.57)^{*}$ \\
\hline Richer & $3.43(1.25,9.44)$ & & $2.18(0.76,6.3)$ & & $2.18(0.69,6.81)$ \\
\hline Richest & $4.89(1.77,13.54)$ & & $2.73(0.8,9.29)$ & & $1.99(0.44,9.09)$ \\
\hline \multicolumn{6}{|l|}{ Husband education } \\
\hline No education & $0.28(0.11,0.77)$ & & $0.97(0.28,3.30)$ & & $1.02(0.29,3.61)$ \\
\hline Primary & $0.35(0.13,0.92)$ & & $0.91(.28,2.93)$ & & $0.97(0.28,3.26)$ \\
\hline Secondary & $0.09(0.03,0.34)$ & & $0.17(0.04,0.68)$ & & $0.17(0.04,0.68)^{*}$ \\
\hline Higher & 1 & & 1 & & 1 \\
\hline \multicolumn{6}{|l|}{ Place of residence } \\
\hline Urban & 1 & & & 1 & 1 \\
\hline Rural & $0.34(0.19,0.58)$ & & & $0.91(0.40,2.05)$ & $0.82(0.25,2.64)$ \\
\hline \multicolumn{6}{|l|}{ Distance to the HF } \\
\hline Far & 1 & & & 1 & 1 \\
\hline Near & $2.57(1.39,4.74)$ & & & $2.03(1.05,3.92)$ & $1.92(0.97,3.78)$ \\
\hline Proportion of women employed $\odot$ & $1.02(1.01,1.03)$ & & & $1.01(1.00,1.02)$ & $1.010(.99,1.02)$ \\
\hline \multicolumn{6}{|l|}{ Community-level of poverty } \\
\hline Low & 1 & & & 1 & 1 \\
\hline Middle & $0.62(0.31,1.17)$ & & & $1.32(0.60,2.82)$ & $1.54(0.68,3.44)$ \\
\hline
\end{tabular}


Table 3 Multilevel logistic regression analysis of individual and community-level factors associated with PNC in Ethiopia, EDHS 2016 (Continued)

\begin{tabular}{|c|c|c|c|c|c|}
\hline Individual and community level characteristics & COR $(95 \% \mathrm{Cl})$ & $\begin{array}{l}\text { Model } 0 \\
\boldsymbol{n}=4242 \\
\mathrm{ICC}=42 \%\end{array}$ & $\begin{array}{l}\text { Model } 1 \\
\text { AOR }(95 \% \mathrm{Cl}) \\
\boldsymbol{n}=4000\end{array}$ & $\begin{array}{l}\text { Model } 2 \\
\text { AOR(95\% Cl) } \\
\boldsymbol{n}=4206\end{array}$ & $\begin{array}{l}\text { Model } 3 \\
\text { AOR (95\% Cl) } \\
\boldsymbol{n}=3967\end{array}$ \\
\hline High & $0.31(0.16,0.60)$ & & & $0.92(0.38,2.16)$ & $1.59(0.60,4.23)$ \\
\hline \multicolumn{6}{|l|}{ Community-level of education } \\
\hline Low & 1 & & & 1 & 1 \\
\hline Middle & $1.64(0.68,3.88)$ & & & $1.32(0.58,3.01)$ & $1.02(0.44,2.34)$ \\
\hline High & $4.29(2.05,8.97)$ & & & $2.56(1.14,5.73)$ & $2.53(1.06,6.06)^{*}$ \\
\hline $\begin{array}{l}\text { The proportion of women with the } \\
\text { opposite attitude to wife-beating } \odot\end{array}$ & $1.01(1.00,1.02)$ & & & $1.0(0.99,1.01)$ & $1.00(0.98,1.01)$ \\
\hline \multicolumn{6}{|l|}{ Community-level of HSU } \\
\hline Low & 1 & & & & 1 \\
\hline High & $3.75(1.93,7.26)$ & & & $2.25(1.16,4.4)$ & $2.32(1.14,4.73)^{*}$ \\
\hline
\end{tabular}

Key: ${ }^{*}=P$-value

$<0.05,{ }^{* *}=P$-value $<0.01, \mathrm{AOR}=$ Adjusted odds ratio and $\odot=$ Continuous Variable, HSU $=$ Health service utilization $1=$ Reference

\section{Random effects (measures of variation)}

There was a significant variation in the utilization of PNC across the communities (clusters). The ICC showed that $42 \%$ of the variation in utilization of PNC was linked to community-level factors. The full model, after adjusting for individual and community level factors, showed that the variation in PNC utilization across communities remained statistically significant. About $37 \%$ of the PNC use variation across communities was explained in the full model. Besides, the MOR confirmed that PNC utilization was attributed to community-level factors. The MOR for PNC utilization was 3.97 in the empty model; these show that there was variation between communities (clustering) (Table 4).

\section{Discussion}

In this study, the educational status of the husband, number of ANC visits, wealth index, community level of education and community level of health service utilization were significant determinants of PNC utilization. This study showed that the ANC visit was positively associated with PNC utilization. The finding is similar to different studies conducted in different parts of Ethiopia [33, 34]. It is also consistent with a study conducted in Tanzania [35]. There was also a similar report in studies Nepal [36] and India [6]. The possible reason behind this could be, the characteristics that predispose women to seek ANC service could also make them more likely to seek PNC service. Besides, those women who were using ANC service could be familiar with other maternal health service and it might also create an opportunity for health professionals to provide counseling regarding the significance of PNC services [23, 33].

The household wealth index was another positively associated variable. Postpartum women who belong to the middle household wealth quintile were more likely to use PNC. The finding is similar to different studies conducted in Gondar [37], Swaziland [38], and Nepal [36]. The possible explanation for this might be women would be improved educationally, economically and socially which would create a better opportunity for seeking health care [31]. Moreover, it would provide women with economic opportunities to afford the cost of health care for health services that may not be free in public

Table 4 Result from a random intercept model (a measure of variation) for PNC at cluster level by multilevel logistic regression analysis, EDHS 2016

\begin{tabular}{lllll}
\hline Measure of variation & Model 0 (Null model) $(95 \% \mathrm{Cl})$ & Model 1 $(95 \% \mathrm{Cl})$ & Model 2 $(95 \% \mathrm{Cl})$ & Model3 (Full model) $(95 \% \mathrm{Cl})$ \\
\hline Variance & 2.37 & 1.77 & 1.52 & 1.50 \\
Explained variation (PCV) (\%) & Ref. & 25 & 35 & 37 \\
ICC (\%) & $42(30.00,53.99)$ & $35(24.62,45.37)$ & $32(22.33,41.66)$ & $31(21.39,40.61)$ \\
MOR & $3.97(3.85,4.09)$ & $3.42(3.31,3.2)$ & $3.18(3.08,3.27)$ & $3.15(3.05,3.24)$ \\
Model fitness & & & & -451.52 \\
Log-likelihood & -552.68 & -466.41 & -525.29 & \\
\hline
\end{tabular}

Model $0=$ without independent variables (null model), Model $1=$ only individual-level variables, Model $2=$ only community-level variables, Model $3=$ both individual and community-level variables, PCV Proportional change in variance, ICC Intra-class correlation coefficient and MOR Median odds ratio 
health institutions [24]. On the other hand, the poorest people would be reluctant about their health care because they might be hopeless since they are still running for their basic needs. But a study conducted in Nigeria showed that women who belonged to the poorest wealth quintile were more likely to use PNC [39]. The discrepancy might be due to the difference in sociodemographic characteristics, method of analysis, sample size and study time variation.

Husband education was also positively associated with PNC utilization. This result is consistent with studies conducted in Amhara regional hospitals [27], a systematic review in developing countries [8] and West African countries [24]. There was also a similar report from studies conducted in Nigeria [39] and Nepal [40]. The possible justification behind this could be educated husband may have better communication with their wives and they may have the willingness to discuss the use of PNC service as well as other maternal health services. This may also provide more autonomy to their wives [33].

Community-level of education was one of the community-level variables which had a significant association with PNC. Women who live in a community with high education levels were more likely to have PNC utilization. This finding is similar to studies conducted in West African counties [24] and India [41]. The reason for this could be the women who live in such a community would be better informed about the benefits of PNC utilization as well as health risks of non-utilization of the service and more empowered to seek healthcare [24, 31]. Furthermore, it could be because of education has a valuable input in enhancing female autonomy that helps women develop greater confidence and capability to make decisions about their health [26]. Community-level of health service utilization was also significantly associated with PNC. Likewise, a study conducted in Tanzania revealed similar findings [42]. This could be because of the community which has a good habit of health service utilization could have better behavior to utilize PNC services and health providers might recommend them about PNC while receiving other health services.

The study also indicated that there was a statistical significant correlation between observations found in the same cluster. About more than one-third of PNC use variation across communities was explained in the full model. The MOR for PNC utilization showed that there was variation between communities (clustering).

This study was conducted by using multilevel mixedeffects logistic regression analysis that can be able to identify the multilevel factors of PNC service utilization and provides important insight to design interventions. Not only this, but it is also more representative of the entire population of Ethiopia since it was taken from all regions and administrative towns. Despite its strength, the findings of the current study have limitations. Due to the use of secondary data, important variables like cultural beliefs in the postpartum period, Knowledge about postpartum danger signs were not available in the dataset, so these variables were not included in the analysis.

\section{Conclusion}

The study also indicated that there was a statistically significant correlation between observations found in the same cluster. In addition to this, MOR for PNC utilization showed that there was variation between communities (clustering). Both individual and community-level factors were significant determinants of PNC utilization. From individual-level factors; the number of ANC visits, educational status of the husband and wealth index were significantly associated. From community-level factors, community level of education and community level of health service utilization was significantly associated with PNC service utilization. The educational status of a woman did not only affect the health of a woman herself, rather it goes to other women in that particular community. Based on the finding of this research, the following recommendations were forwarded: Design and implement policies that will strengthen women's education at a different level of the population, improve the existing strategies of focused antenatal care for all pregnant women, increase and sustain utilization of all health services in all service delivery points, continuous and special attention should be given to the poorest population, emphasis should be given to the educational status of the husband, to strengthen health-seeking behaviors of the population, further qualitative research is needed to explore different cultural beliefs during the postpartum period which may prevent the women to seek PNC services, to conduct spatial analysis for giving appropriate area-specific intervention.

\section{Abbreviations \\ CSA: Central Statistical Agency; EDHS: Ethiopia Demographic and Health Survey; PNC: Postnatal Care; WHO: World Health Organization}

\section{Acknowledgements \\ We would like to express my deepest gratitude to Wollo University College of Medicine and Health Science for sponsoring this research. A special word of thank extended Central Statistical Agency of Ethiopia for giving the EDHS dataset and authorize me to conduct the research.}

\section{Authors' contributions}

BA: Initiated the research and analysis data, GF: Write the result, GW: Write and draft the manuscript. MY: Edit and revise the manuscript. The author(s) read and approved the final manuscript.

\section{Funding}

Not applicable.

\section{Availability of data and materials}

The datasets used and/or analyzed during this study is available from the corresponding author on reasonable request. 


\section{Ethics approval and consent to participate}

Ethical approval was obtained from the Ethical Review Committee of Wollo University, College of Medicine and Health Sciences. Authorization letter was also obtained from CSA for downloading the EDHS data set by requesting the website www.measuredhs.com. The data was used only for this study and it was not passed to other researchers. All data were treated as confidential and no need to identify any household or individual respondent interviewed in the survey. The detailed information on methodology and the ethical issue was published in the EDHS report.

\section{Consent for publication}

Not applicable.

\section{Competing interests}

The authors declare that they have no competing interests.

\section{Author details}

'Department of Biostatistics and Epidemiology, School of Public Health, College of Medicine and Health Sciences, Wollo University, Dessie, Ethiopia. ${ }^{2}$ Department of Reproductive and Family Health, School of Public Health, College of Medicine and Health Sciences, Mekelle University, Mekelle, Ethiopia. ${ }^{3}$ Department of Reproductive and Family Health, School of Public Health, College of Medicine and Health Sciences, Wollo University, Dessie, Ethiopia.

Received: 12 January 2020 Accepted: 25 March 2020

\section{Published online: 15 April 2020}

\section{References}

1. Unumeri $\mathrm{G}$, Ishaku SM. Delivering contraceptive vaginal rings: Review of postpartum and postnatal care programs in Nigeria. Abuja: Population Council; 2015. https://doi.org/10.31899/rh9.1016.

2. Warren C, Daly P, Toure L, Mongi P. Postnatal care. In: Lawn J, Kerber K, editors. Opportunities for Africa's newborns : practical data, policy and programmatic support for newborn care in Africa. Geneva: WHO on behalf of The Partnership for Maternal, Newborn and Child Health; 2006. 79-90. http://hdl.handle.net/1854/LU-5897296.

3. World Health Organization. WHO recommendations on newborn health guidelines approved by the WHO Guidelines Review Committee: World Health Organization; 2017. https://apps.who.int/iris/handle/10665/259269.

4. Lwelamira J, Safari J, Stephen A. Utilization of maternal postnatal care services among women in selected villages of Bahi District, Tanzania. Curr Res J Soc Sci. 2015;7(4):106-11.

5. World Health Organization. WHO recommendations on postnatal care of the mother and newborn: World Health Organization; 2014. p. 62. ISBN 9789241506649 . https://apps.who.int/iris/handle/10665/97603.

6. Singh A, Kumar A, Pranjali P. Utilization of maternal healthcare among adolescent mothers in urban India: evidence from DLHS-3. PeerJ. 2014;2: e592. https://doi.org/10.7717/peerj.592.

7. Jat $\mathrm{TR}, \mathrm{Ng} \mathrm{N}$, San Sebastian M. Factors affecting the use of maternal health services in Madhya Pradesh state of India: a multilevel analysis. Int J Equity Health. 2011;10:59. https://doi.org/10.1186/1475-9276-10-59.

8. Adhikari C, Yadav RK, Timilshina P, Ojha R, Gaire D, Ghimire A. Proportion and factors affecting for post-natal care utilization in developing countries: a systematic review. J Manmohan Mem Inst Health Sci. 2016;2:14-9. https:// doi.org/10.3126/jmmihs.v2i0.15791.

9. Çalıkan Z, Kılı D, Öztürk S, Atılgan E. Equity in maternal health care service utilization: a systematic review for developing countries. Int J Public Health. 2015;60(7):815-25 Published online 2015 Aug 23.

10. Belemsaga DY, Kouanda S, Goujon A, Kiendrebeogo JA, Duysburgh E, Degomme $\mathrm{O}$, et al. A review of factors associated with the utilization of healthcare services and strategies for improving postpartum care in Africa. 2015;28(2):83-105. https://doi.org/10.21825/af.v28i2.4866.

11. Central Statistical Agency (CSA) [Ethiopia] and ICF. Ethiopia Demographic and Health Survey 2016. Addis Ababa and Rockville: CSA and ICF; 2016.

12. World Health Organization. WHO Postnatal Care of the Mother and Newborn; 2013. p. 2013.

13. Lawn JE. Katarzyna Wilczynska-Ketende, Simon N. Cousens. Estimating the causes of 4 million neonatal deaths in the year 2000. Int J Epidemiol. 2006; 35(3):706-18. Published online 2006 Mar 23. https://doi.org/10.1093/ije/ dyl043.
14. Stanton C, Lawn JE, Rahman H, Wilczynska-Ketende K, Hill K. Stillbirth rates: delivering estimates in 190 countries. Lancet. 2006 May 6;367(9521):1487-94. https://doi.org/10.1016/S0140-6736(06)68586-3.

15. Assembly G. Sustainable Development goals. SDGs, Transforming our world: the, vol. 2030; 2015.

16. Mullan Z. Transforming health care in Ethiopia. Lancet Glob Health. 2016 Jan;4(1):e1. https://doi.org/10.1016/S2214-109X(15)00300-9.

17. Health FDRoEMo. HSTP health sector transformation plan 2015/16-2019/20 (2008-2012 EFY). Addis Ababa: Federal Democratic Republic of Ethiopia Ministry of Health; 2015.

18. Deepak CNJHD. A Study on utilization of maternal health services and factors influencing the utilization in urban slums of Lucknow. Int J Med Public Health. 2018;8(2):77-81. https://doi.org/10.5530/ijmedph.2018.2.17.

19. Saol T. Prevalence of Postnatalcare utilization and associated factors among postnatal mothers in Sodo Zuria District, Wolaita zone, South Ethiopia, 2016: Addis Ababa University; 2016.

20. Angore BN, Tufa EG, Bisetegen FS. Determinants of postnatal care utilization in urban community among women in Debre Birhan town, northern Shewa, Ethiopia. J Health Popul Nutr. 2018;37:10. https://doi.org/10.1186/ s41043-018-0140-6.

21. Babalola S, Fatusi A. Determinants of use of maternal health services in Nigeria-looking beyond individual and household factors. BMC pregnancy and childbirth. 2009;9(1):43. https://doi.org/10.1186/1471-2393-9-43.

22. Rwabufigiri BN, Mukamurigo J, Thomson DR, Hedt-Gautier BL, Semasaka JPS Factors associated with postnatal care utilisation in Rwanda: a secondary analysis of 2010 demographic and health survey data. BMC pregnancy and childbirth. 2016;16(1):122. https://doi.org/10.1186/s12884-016-0913-0.

23. Mekonnen ZA, Lerebo WT, Gebrehiwot TG, Abadura SA. Multilevel analysis of individual and community level factors associated with institutional delivery in Ethiopia. BMC research notes. 2015;8:376. https://doi.org/10.1186/ s13104-015-1343-1.

24. Solanke BL, Emmanuel O. Amoo, Adenike Esther Idowu . Improving Postnatal Check-Ups for Mothers in West Africa: a Multilevel Analysis. Women Health. 2017. Published online 2017 Feb 7. https://doi.org/10.1080/03630242.2017.1292343.

25. Belachew T, Taye A, Belachew T. Postnatal care service utilization and associated factors among mothers in Lemo Woreda, Ethiopia. J Women's Health Care. 2016;5(10.4172):2167-0420.1000318. https://doi.org/10.4172/ 2167-0420.1000318.

26. Workineh YG, Hailu DA. Factors Affecting Utilization of Postnatal Care Service in Amhara Region, Jabitena District, Ethiopia, Science. J Public Health. 2014;2(3):169-76. https://doi.org/10.11648/j.sjph.20140203.15.

27. Timerga G, Hailemeskel S. Trend Analysis on Maternal Health Care Services Utilization in Amhara Region Referral Hospitals, Ethiopia. Int J Nutr Food Sci. 2018;7(3):81-9. https://doi.org/10.11648/j.jphfs.20180703.11.

28. Commission PC. The 2007 population and housing census of Ethiopia. 2010

29. Ethiopia C. Summary and statistical report of the 2007 population and housing census. Addis Ababa: Federal democratic republic of Ethiopia population census commission; 2008. p. 1-0.

30. Varma DS, Khan M, Hazra A. Increasing postnatal care of mothers and newborns including follow-up cord care and thermal care in rural Uttar Pradesh. J Fam Welf. 2010:56:31-42.

31. Tiruneh FN, Chuang K-Y, Chuang Y-C. Women's autonomy and maternal healthcare service utilization in Ethiopia. BMC Health Serv Res. 2017;17(1): 718. https://doi.org/10.1186/s12913-017-2670-9.

32. Hox J, Moerbeek M, van de Schoot R. Multilevel analysis: techniques and applications, third edition (quantitative methodology series). New York: Routledge; 2018.

33. Tarekegn SM, Lieberman LS, Giedraitis V. Determinants of maternal health service utilization in Ethiopia: analysis of the 2011 Ethiopian Demographic and Health Survey. BMC Pregnancy Childbirth. 2014;14(1):161. https://doi. org/10.1186/1471-2393-14-161.

34. Asrat AA, Mengistu A. Factors associated with utilization of institutional delivery care and postnatal care services in Ethiopia. J Public Health Epidemiol. 2018;10(4):108-22. https://doi.org/10.5897/jphe2017.0989.

35. Kanté AM, Chung CE, Larsen AM, Exavery A, Tani K, Phillips JF. Factors associated with compliance with the recommended frequency of postnatal care services in three rural districts of Tanzania. BMC Pregnancy Childbirth. 2015;15(1):341. https://doi.org/10.1186/s12884-015-0769-8 PMID: 26689723; PMCID: PMC4687308.

36. Khanal V, Adhikari M, Karkee R, Gavidia T. Factors associated with the utilization of postnatal care services among the mothers of Nepal: analysis 
of Nepal Demographic and Health Survey 2011. BMC Women's Health. 2014;14(1):19. https://doi.org/10.1186/1472-6874-14-19.

37. Worku AG, Yalew AW, Afework MF. Factors affecting the utilization of skilled maternal care in Northwest Ethiopia: a multilevel analysis. BMC Int Health Hum Rights. 2013;13(1):20. https://doi.org/10.1186/1472-698X-13-20.

38. Tsawe M, Moto A, Netshivhera T, Ralesego L, Nyathi C, Susuman AS. Factors influencing the use of maternal healthcare services and childhood immunization in Swaziland. Int J Equity Health. 2015;14(1):32. https://doi. org/10.1186/s12939-015-0162-2 PMID: 25889973; PMCID: PMC4391603.

39. Takai IU, Dlakwa HD, Bukar M, Audu BM, Kwayabura AS. Factors responsible for under-utilization of postnatal care services in Maiduguri, north-eastern Nigeria. Sahel Med J. 2015;18:109-15. https://doi.org/10.4103/1118-8561. 169282 Available from: http://www.smjonline.org/text.asp?2015/18/3/109/16 9282/ Cited 2020 Mar 12

40. Khadka R, Hong SA, Thepthien B, Author C, Ah S, Email H. Postnatal care service utilization and its determinants in Ramechhap district, Nepal : A community-based cross-sectional study. J PH Dev. 2017;15(3):1-16.

41. Srivastava S, Singh S, Upadhyay AK. Comparing relative effect of human resource and economic resource on utilization of maternal health Care Services in India : a multilevel analysis. IOSR_. J Humanit Soc Sci. 2017;22(8): 71-80.

42. Mohan D, Gupta S, LeFevre A, Bazant E, Killewo J, Baqui AH. Determinants of postnatal care use at health facilities in rural Tanzania: a multilevel analysis of a household survey. BMC Pregnancy Childbirth. 2015;15(1):282. https://doi.org/10.1186/s12884-015-0717-7 PMID: 26518337; PMCID: PMC4628262.

\section{Publisher's Note}

Springer Nature remains neutral with regard to jurisdictional claims in published maps and institutional affiliations.

Ready to submit your research? Choose BMC and benefit from:

- fast, convenient online submission

- thorough peer review by experienced researchers in your field

- rapid publication on acceptance

- support for research data, including large and complex data types

- gold Open Access which fosters wider collaboration and increased citations

- maximum visibility for your research: over $100 \mathrm{M}$ website views per year

At BMC, research is always in progress.

Learn more biomedcentral.com/submissions 